\title{
Familial Mediterranean Fever and Multiple Sclerosis Successfully Treated With Interferon Beta-1a: A Case Report
}

\author{
Bilgin ÖZTÜRK(1) \\ Department of Neurology, Gülhane Training and Research Hospital, Ankara, Turkey
}

\begin{abstract}
Multiple sclerosis (MS) is the most common demyelinating disease in Turkey while familial Mediterranean fever (FMF) is the most common periodic fever syndrome worldwide. In this article, we report a 37-year-old male patient admitted with complaint of difficulty in walking. He had been taking colchicine at admission for 27 years. Despite this therapy, he had been experiencing twice monthly severe FMF attacks. After systemic and neurological examinations, laboratory tests and cranial and spinal magnetic resonance imaging, he was diagnosed as MS. Interferon (IFN) beta-1a was initiated three times/weekly subcutaneously for MS treatment. He stopped colchicine treatment after five months of IFN treatment because he did not suffer from any FMF attacks. He is still attack free for both diseases for a follow-up duration of 12 months. IFN beta is one of the most preferred agents for MS treatment but not one of the agents used for the treatment of FMF. Interferon beta can be a treatment of choice in patients with coincident FMF and MS and can be used in colchicine-resistant patients after being studied in systematic clinical studies.

Keywords: Familial Mediterranean fever, interferon beta, multiple sclerosis.
\end{abstract}

Familial Mediterranean fever (FMF) is an autosomal recessive autoinflammatory disorder. It is characterized by recurrent attacks of fever, peritonitis, pleuritis, and synovitis and common in Mediterranean people including Turks, Arabs, Armenians, and non-Ashkenazi Jews. ${ }^{1}$ The responsible gene for FMF is MEFV located on chromosome $16 \mathrm{p}$.

Multiple sclerosis (MS) is the most common demyelinating disease of central nervous system. MS is characterized by inflammation and demyelination and caused by several environmental and genetic factors. Patients with FMF have a susceptibility to develop MS. Mutations of genes like MEFV encoding pyrin protein may promote development of MS disease. ${ }^{2}$ AkmanDemir et al. ${ }^{3}$ suggested a four-fold increased rate of FMF among MS patients. Currently, there is no curative treatment for both diseases. Immunomodulatory drugs display beneficial effects by decreasing severity and frequency of MS attacks.

\section{CASE REPORT}

A 37-year-old male patient was admitted to our department with numbness of lower extremities and difficulty in walking in September 2017. He had been suffering from numbness for more than three months and from gait disturbance for the last month. A few years before, he had numbness on lower extremities but he did not admit to any hospital and his complaints were completely resolved within two weeks. In his neurological examination, hypoesthesia in right

Received: October 29, 2018 Accepted: January 23, 2019 Published online: April 22, 2019

Correspondence: Bilgin Öztürk, MD. Gülhane Eğitim ve Araştırma Hastanesi Nöroloji Kliniği, 06010 Keçiören, Ankara, Turkey. Tel: +90532-5785730 e-mail: drbilgin@gmail.com

\section{Citation:}

Öztürk B. Familial mediterranean fever and multiple sclerosis successfully treated with interferon beta-1a: A case report. Arch Rheumatol 2019;34(4):443-446. 


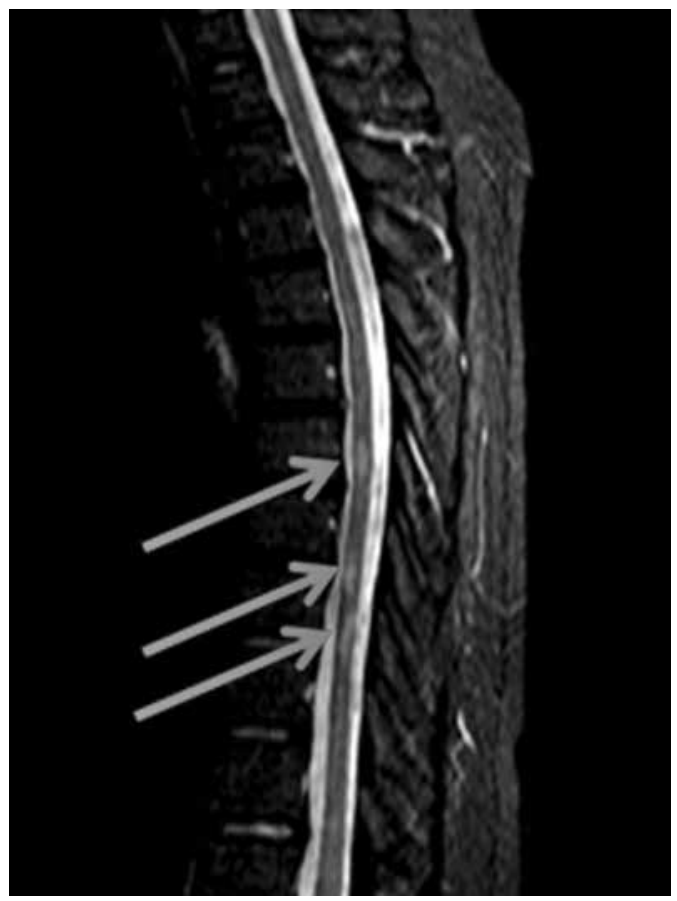

Figure 1. Spinal plaques at level of $T_{8}-T_{10}$ and $\mathrm{T}_{11}$.

side of the body under $\mathrm{T}_{8}$ dermatome and $4 / 5$ paraparesis in lower extremities were detected. Deep tendon reflexes were hyperactive in lower extremities. Babinski sign were positive bilaterally. His cerebellar examination showed ataxic gait. A written informed consent was obtained from the patient.

In his past medical history, he was diagnosed with FMF 27 years ago. M694V and V726A mutations on MEFV gene were detected in his gene analysis. Anakinra was added to his treatment due to inadequate response to maximal dose of colchicine. He had used anakinra for two months and anakinra treatment had been stopped because of its side effects. However, he continued colchicine treatment $(1.5 \mathrm{mg} / \mathrm{day})$. Despite this treatment, he had been suffering from abdominal pain, fever, and arthralgia attacks twice monthly.

Cranial and spinal magnetic resonance imaging (MRI) showed multiple demyelinating plaques. Thoracal and cranial plaques were not enhancing with contrast agent. Spinal plaques were at the level of $\mathrm{T}_{8}-\mathrm{T}_{10}$ and $\mathrm{T}_{11}$ (Figures 1 and 2). Oligoclonal immunoglobulin (Ig) G bands (type II) were detected by immunofixation electrophoresis in cerebrospinal

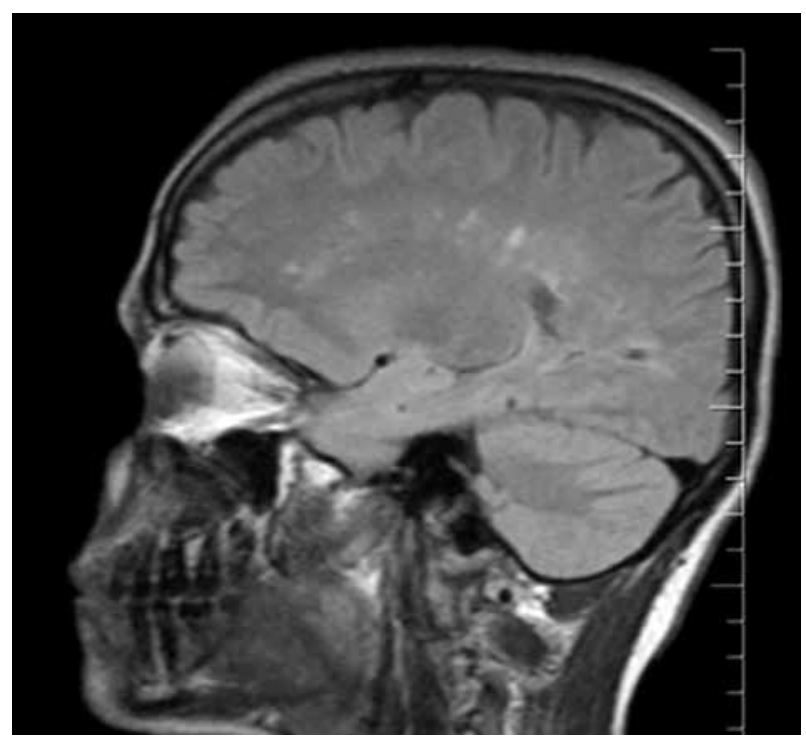

Figure 2. Cranial plaques on sagittal sequence of magnetic resonance imaging.

fluid (CSF). Neuromyelitis optica IgG was not found in CSF. Right tibial sensorial evoked potential latency was 64.2 milliseconds and left tibial potential latency was 46.1 milliseconds. He was diagnosed as MS and treated with $1000 \mathrm{mg} /$ daily corticosteroid therapy for seven consecutive days. His hypoesthesia was completely resolved while paraparesis was almost resolved. However, his gait was still ataxic. Interferon (IFN) beta-1a was initiated three times/weekly subcutaneously. On monthly follow-ups, there was no attack for MS. The patient discontinued colchicine treatment by his own will after five months of IFN treatment because he did not suffer from any FMF attacks. He did not suffer even a mild FMF attack from september 2017 until now. He is also under control for MS.

\section{DISCUSSION}

Neurological involvement of FMF is rare, including headaches, aseptic meningitis, electroencephalography abnormalities, and pseudotumor cerebri. ${ }^{4}$ Demyelinating diseases rarely coexist with FMF. ${ }^{5-7}$ Karabudak et al. $^{8}$ evaluated 17 patients with FMF for neurologic complications but could not describe MS-like demyelinating plaques. Akman Demir et al. ${ }^{3}$ found 12 FMF patients (9 with MS and 3 with non-MS 
demyelinating diseases) by evaluating 2,800 MS patients. They suggested a four-fold increased rate of FMF among patients with MS and reported that the presence of MEFV variations could change the incidence and progression of other inflammatory diseases. They also found that the duration between the onset of neurologic disorders and FMF was nearly 20 years.

Colchicine is the mainstay of FMF treatment due to its proven efficacy in reducing frequency of attacks and prevention of amyloidosis in almost all cases. In colchicine non-responder patients, biologic agents are used with their effect on inhibition of interleukin (IL)-1, IL-6, and tumor necrosis factor (TNF)-alpha. A Cochrane review evaluating drugs used for colchicineresistant FMF (anakinra, rilonacept, etanercept, infliximab, thalidomide, IFN-alpha, herbal dietary supplements, and non-steroidal anti-inflammatory drugs) concluded that there were still limited randomized controlled studies for the treatment of FMF. ${ }^{9}$ Few studies consisting of limited cases showed benefits with IFN-alpha. IFN prevented most of the FMF attacks or attenuated the attack intensity. ${ }^{10-12}$ However, Tunca et al. ${ }^{13}$ could not demonstrate a clear effect of IFN in FMF patients after a double blind placebo controlled trial.

"Familial Mediterranean fever" and "Multiple sclerosis" were used as keywords for the literature search strategy through MEDLINE/PubMed databases. Few cases were detected in the literature about FMF and MS coexistence. Most of these reports do not provide any information about immunomodulating/immunosuppressive therapies for MS. ${ }^{5-6,14-16}$ In some cases, therapies for MS were reported while their effects on FMF attacks were not. ${ }^{17,18}$ Ceylan et al. $^{19}$ reported two cases of FMF with MS. MS diagnosis was established by cervical MRI findings and oligoclonal band results in one case and by cranial MRI findings in the other case. However, these findings did not fulfill MS diagnosis criteria. Furthermore, none of these reports provide information about the benefit of treatment ordered for MS on FMF attacks.

Our patient was suffering from frequent FMF attacks despite appropriate treatments. After initiating IFN beta-1a for MS, he did not have even a single mild attack of FMF for five months, which led him to discontinue colchicine despite all our advice. Even after stopping colchicine, he did not suffer from any FMF attacks for 12 months. Erythrocyte sedimentation rate was $16,8,23,11$, and $14 \mathrm{~mm} /$ hour on his follow-ups at zero, three, six, nine, and 12 months during the last 12 months. Proteinuria was not observed in 24-hour urine protein test 12 months after IFN treatment initiation $(78 \mathrm{mg} /$ day). Glomerular filtration rate was also normal $\left(95 \mathrm{~mL} / \mathrm{min} / 1.73 \mathrm{~m}^{2}\right)$.

Familial Mediterranean fever is mediated mainly by IL-1 pathway by activation of inflammasomes. IFN-beta plays an important role in the innate immune system. IFN-beta inhibits secretion of pro-inflammatory cytokines such as IL-1, IL-6, and TNF-alpha and also expression of variety of inflammasomes which may explain the observed efficacy in our case..$^{20,21}$ IFN-beta was effective in our patient for both MS and FMF. Our patient discontinued colchicine treatment in contrast to our recommendation. Colchicine treatment should be continued due to high risk of amyloidosis which is not related to frequency of attacks. It is too early to say that IFN beta is another choice for the treatment of colchicineresistant FMF and further studies are needed to verify this hypothesis.

\section{Declaration of conflicting interests}

The author declared no conflicts of interest with respect to the authorship and/or publication of this article.

\section{Funding}

The author received no financial support for the research and/or authorship of this article.

\section{REFERENCES}

1. Medlej-Hashim M, Nehme N, Chouery E, Jalkh N, Megarbane A. 1Novel MEFV transcripts in Familial Mediterranean fever patients and controls. BMC Med Genet 2010;11:87.

2. Aksu K, Keser G. Coexistence of vasculitides with familial Mediterranean fever. Rheumatol Int 2011;31:1263-74.

3. Akman-Demir G, Gul A, Gurol E, Ozdogan H, Bahar $\mathrm{S}$, Oge $\mathrm{AE}$, et al. Inflammatory/demyelinating central nervous system involvement in familial Mediterranean fever (FMF): coincidence or association? J Neurol 2006;253:928-34.

4. Schwabe AD, Monroe JB. Meningitis in familial Mediterranean fever. Am J Med 1988;85:715-7. 
5. Topçuoğlu MA, Karabudak R. Familial Mediterranean fever and multiple sclerosis. J Neurol 1997;244:510-4.

6. Ugurlu S, Bolayir E, Candan F, Gumus C. Familial mediterranean fever and multiple sclerosis--a case report. Acta Reumatol Port 2009;34:117-9.

7. Sayin R, Alpayci M, Soyoral YU. A case with multiple sclerosis and familial Mediterranean fever. Genet Couns 2011;22:309-12.

8. Karabudak R, Dogulu CF, Nurlu G, Simsek H, Saatci I. Central nervous system demyelination in familial Mediterranean fever: is it a coincidence? Eur J Neurol 2003;10:327-8.

9. Wu B, Xu T, Li Y, Yin X. Interventions for reducing inflammation in familial Mediterranean fever. Cochrane Database Syst Rev 2015;3:CD010893.

10. Tunca M, Tankurt E, Akbaylar Akpinar H, Akar S, Hizli N, Gönen O. The efficacy of interferon alpha on colchicine-resistant familial Mediterranean fever attacks: a pilot study. Br J Rheumatol 1997;36:1005-8.

11. Calguneri M, Apras S, Ozbalkan Z, Ozturk MA, Ertenli I, Kiraz S. The efficacy of continuous interferon alpha administration as an adjunctive agent to colchicineresistant familial Mediterranean fever patients. Clin Exp Rheumatol 2004;22:41-4.

12. Tweezer-Zaks N, Rabinovich E, Lidar M, Livneh A. Interferon-alpha as a treatment modality for colchicine- resistant familial Mediterranean fever. J Rheumatol 2008;35:1362-5.

13. Tunca M, Akar S, Soytürk M, Kirkali G, Resmi $\mathrm{H}$, Akhunlar $\mathrm{H}$, et al. The effect of interferon alpha administration on acute attacks of familial Mediterranean fever: A double-blind, placebocontrolled trial. Clin Exp Rheumatol 2004;22:37-40.

14. Unal A, Emre U, Dursun A, Aydemir S. The co-incidence of multiple sclerosis in a patient with familial Mediterranean fever. Neurol India 2009;57:672-3.

15. Yücesan $C$, Canyiğit $A$, Türkçapar N. The coexistence of familial Mediterranean fever with multiple sclerosis. Eur J Neurol 2004;11:716-7.

16. Canpolat M, Gumus H, Gunduz Z, Dusunsel R, Kumandas S, Bayram AK, et al. Neurological Manifestations in Familial Mediterranean Fever: Results of 22 Children from a Reference Center in Kayseri, an Urban Area in Central Anatolia, Turkey. Neuropediatrics 2017;48:79-85.

17. Russo M, Naro A, Dattola V, Gallizzi R, Calabrò RS, Buccafusca M. Familiar Mediterranean fever and multiple sclerosis: an unreported association in the Italian population? Neurol Sci 2015;36:811-2.

18. Yahalom G, Kivity S, Lidar M, Vaknin-Dembinsky A, Karussis D, Flechter S, et al. Familial Mediterranean fever (FMF) and multiple sclerosis: an association study in one of the world's largest FMF cohorts. Eur J Neurol 2011;18:1146-50.

19. Ceylan G, Erten S, Ercan K. Co-existence of familial Mediterranean fever and multiple sclerosis in two patients. Acta Reumatol Port 2014;39:342-4.

20. Rothuizen LE, Buclin T, Spertini F, Trinchard I, Munafo A, Buchwalder PA, et al. Influence of interferon beta1a dose frequency on PBMC cytokine secretion and biological effect markers. $J$ Neuroimmunol 1999;99:131-41.

21. Noroozi S, Meimand HAE, Arababadi MK, Nakhaee $\mathrm{N}$, Asadikaram G. The Effects of IFN- $\beta$ 1a on the Expression of Inflammasomes and ApoptosisAssociated Speck-Like Proteins in Multiple Sclerosis Patients. Mol Neurobiol 2017;54:3031-7. 